OPEN ACCESS

Edited by:

Tamas Fulop,

Université de Sherbrooke, Canada

Reviewed by:

Safikur Rahman,

Yeungnam University, South Korea

Maria Bullido,

Universidad Autónoma de Madrid,

Spain

*Correspondence:

Ruth F. Itzhaki

ruth.itzhaki@manchester.ac.uk

Received: 29 March 2018 Accepted: 25 September 2018 Published: 19 October 2018

Citation: Itzhaki RF (2018) Corroboration of a Major Role for Herpes Simplex Virus Type 1 in Alzheimer's Disease. Front. Aging Neurosci. 10:324. doi: 10.3389/fnagi.2018.00324

\section{Corroboration of a Major Role for Herpes Simplex Virus Type 1 in Alzheimer's Disease}

\author{
Ruth F. Itzhaki* \\ Nuffield Department of Clinical Neurosciences, University of Oxford, Oxford, United Kingdom
}

Strong evidence has emerged recently for the concept that herpes simplex virus type 1 (HSV1) is a major risk for Alzheimer's disease (AD). This concept proposes that latent HSV1 in brain of carriers of the type 4 allele of the apolipoprotein E gene (APOE- $\varepsilon 4)$ is reactivated intermittently by events such as immunosuppression, peripheral infection, and inflammation, the consequent damage accumulating, and culminating eventually in the development of $A D$. Population data to investigate this epidemiologically, e.g., to find if subjects treated with antivirals might be protected from developing dementia-are available in Taiwan, from the National Health Insurance Research Database, in which $99.9 \%$ of the population has been enrolled. This is being extensively mined for information on microbial infections and disease. Three publications have now appeared describing data on the development of senile dementia (SD), and the treatment of those with marked overt signs of disease caused by varicella zoster virus (VZV), or by HSV. The striking results show that the risk of SD is much greater in those who are HSV-seropositive than in seronegative subjects, and that antiviral treatment causes a dramatic decrease in number of subjects who later develop SD. It should be stressed that these results apply only to those with severe cases of HSV1 or VZV infection, but when considered with the over 150 publications that strongly support an HSV1 role in AD, they greatly justify usage of antiherpes antivirals to treat AD. Three other studies are described which directly relate to HSV1 and AD: they deal respectively with lysosomal changes in HSV1-infected cell cultures, with evidence for a role of human herpes virus type 6 and 7 (HHV6 and HHV7) in AD, and viral effects on host gene expression, and with the antiviral characteristics of beta amyloid (A $\beta)$. Three indirectly relevant studies deal respectively with schizophrenia, relating to antiviral treatment to target HSV1, with the likelihood that HSV1 is a cause of fibromyalgia (FM), and with FM being associated with later development of SD. Studies on the link between epilepsy, $A D$ and herpes simplex encephalitis (HSE) are described also, as are the possible roles of APOE- 4 , HHV6 and HSV1 in epilepsy.

Keywords: Alzheimer's disease, senile dementia, herpes simplex virus, varicella zoster virus, population epidemiology, anti-herpes antiviral, fibromyalgia, epilepsy 


\section{INTRODUCTION}

The viral concept of Alzheimer's disease (AD) proposes that herpes simplex virus type 1 (HSV1) in brain of apolipoprotein $\mathrm{E}$ gene (APOE- $\varepsilon 4$ ) carriers accounts for some $60 \%$ of cases (Itzhaki et al., 1997). Most of the population is infected with this virus by the age of 70 . The concept postulates that HSV1 travels to the brain probably in middle age, where it remains in a latent state, with very limited transcription and probably very low or zero protein synthesis. Reactivation from latency occurs intermittently, caused by events such as immunosuppression, peripheral infection and inflammation. Accumulation of the consequent damage-direct viral action and major inflammatory effects-leads eventually to the development of AD (Wozniak and Itzhaki, 2010).

The main initial discovery on which this concept was based was that HSV1 DNA was detectable in brain of both AD patients and elderly normal people (i.e., the latter were infected but were asymptomatic; Jamieson et al., 1991), the two groups differing in that most of the $\mathrm{AD}$ patients were APOE- $\varepsilon 4$ carriers (Itzhaki et al., 1997). It was therefore suggested that APOE- $\varepsilon 4$ carriers suffer either greater viral damage on reactivation or have poorer repair of such damage. In a striking parallelism in the PNS, APOE- $\varepsilon 4$ was found to be a risk for cold sores (herpes labialis), which are caused mainly by HSV1 (Itzhaki et al., 1997). Also in genital herpes, caused usually by HSV2, APOE- 44 is a risk for recurrence of genital ulcers (Jayasuriya et al., 2008). The subsequent finding that antibodies to HSV (these are known to be long-lived after herpes simplex encephalitis (HSE)) were present in cerebrospinal fluid from $\mathrm{AD}$ patients and age-matched controls showed that productive HSV1 infection had occurred, indicating that HSV1 is not a passive resident in the central nervous system (CNS; Wozniak et al., 2005). The data cannot be explained by a greater susceptibility of $\mathrm{AD}$ sufferers, or of APOE- $\varepsilon 4$ carriers, to HSV1 infection, as the virus was present in brain at almost the same frequency in $\mathrm{AD}$ patients as in the controls, and was far more frequent among nonAPOE- $\varepsilon 4$ carriers than among APOE- $\varepsilon 4$ carriers in the controls (although admittedly, the numbers in each category were very small).

Links between HSV1 action and AD (Tables 1, 2) include the discovery that the viral DNA is located very specifically within AD plaques (Wozniak et al., 2009a), and that the main component of plaques, beta amyloid $(\mathrm{A} \beta)$, accumulates in HSV1-infected cell cultures (Wozniak et al., 2007; De Chiara et al., 2010; Santana et al., 2012), and in the brains of HSV1-infected mice (Wozniak et al., 2007); subsequently others confirmed and extended these results (see review, Wozniak and Itzhaki, 2010). Taken together, the data suggest that HSV1 is a cause of $A \beta$ products and plaques. We and others have shown too that the main component of tangles-an abnormal form of the protein called tau (P-tau)-accumulates in HSV1-infected cell cultures (Zambrano et al., 2008; Wozniak et al., 2009b; Alvarez et al., 2012).

It should perhaps be stressed that the viral concept does not preclude a major role for $A \beta$ and $\mathrm{P}$-tau in the etiology of $\mathrm{AD}$, even though their effects are still little understood;
TABLE 1 | Main data on herpes simplex virus type 1 (HSV1) and AD from the author's laboratory between 1991 and 2015.

\begin{tabular}{ll}
\hline Discovery & Reference \\
\hline HSV1 DNA detected (by PCR) in brains of elderly &
\end{tabular}

HSV1 DNA detected (by PCR) in brains of elderly

controls and AD patients.

HSV1 in brain of APOE- $\varepsilon 4$ carriers confers high

risk of AD. APOE-e4 is a risk for cold sores. First of several articles showing that APOE genotype modulates extent of microbial damage.

HHV6 DNA is present in AD brains.

Jamieson et al. (1991)

Itzhaki et al. (1997) Intrathecal antibodies to HSV1 found in the elderly, showing that productive infection of HSV1 in brain has occurred.

$A \beta$ accumulation occurs in HSV1-infected cell cultures.

HSV1 DNA is located specifically in amyloid plaques of $A D$ brains.

AD-like tau (P-tau) accumulation occurs in HSV1-infected cell cultures.

HSV1 activates BACE1 via activation of PKR, then phosphorylation of elF2- $\alpha$.

Acyclovir and other HSV1 replication-inhibitors reduce greatly the levels of $A \beta$ and $P$-tau in HSV1-infected cell cultures.

IVIG reduces greatly the levels of $A \beta$ and $P$-tau in HSV1-infected cell cultures.

Helicase primase inhibitor reduces greatly the levels of $A \beta$ and $P$-tau in HSV1-infected cell cultures.

Fucan reduces greatly the levels of $A \beta$ and $P$-tau in HSV1-infected cell cultures.

Interpretation of Taiwan population epidemiological data on HSV and risk of AD and antiherpes effects on development of senile dementia.

instead it suggests a cause of their accumulation-namely, HSV1 infection. Further, in HSV1- infected cells in culture, treatment with various types of antiviral have been found to decrease the level of $A \beta$ and particularly, that of P-tau (see e.g., Wozniak et al., 2011). Usage of antivirals such as acyclovir (ACV), which inhibits viral DNA replication, showed that P-tau formation depends on viral DNA replication, whereas $\mathrm{A} \beta$ formation does not do so; inhibition of the latter by such agents probably occurs via inhibition of virus spread.

\section{DETECTION OF HSV1 IN BRAIN AND EVIDENCE FOR ITS ROLE IN AD}

The presence of HSV1 in brain is central to these concepts. Following its discovery in elderly brains by the author's group, studies by five other groups confirmed its presence there (see review, Wozniak and Itzhaki, 2010). Other data too have provided confirmation-sometimes indirect, from very diverse types of approach (Table 2 and see review, Itzhaki, 2014), including studies on HSV1-infected APOE-transgenic mice or APOE-transfected cell cultures, GWAS, epidemiological investigations on anti-HSV1 IgG and IgM antibodies in serum from $\mathrm{AD}$ patients, or on infectious burden, and measurement of IgG avidity index (Agostini et al., 2016) as an indicator of reactivation (IgG presence indicates infection with HSV1, 
TABLE 2 | Some major discoveries relating to HSV1 and AD between 2005 and 2018.

\begin{tabular}{|c|c|}
\hline Discovery & Reference \\
\hline $\begin{array}{l}\text { Association of cognitive impairment with } \\
\text { HSV1-seropositive APOE- } \varepsilon 4 \text { in aged } \\
\text { cardiovascular patients. }\end{array}$ & Strandberg et al. (2005) \\
\hline $\begin{array}{l}\text { HSV1 load/expression is greater in APOE- } \\
\varepsilon 4 \text { transgenic mice. }\end{array}$ & $\begin{array}{l}\text { Burgos et al. (2006), } \\
\text { Miller and Federoff (2008) } \\
\text { Bhattacharjee et al. (2008) }\end{array}$ \\
\hline $\begin{array}{l}\text { Presence/levels of serum anti-HSV1 antibodies is } \\
\text { associated with AD. }\end{array}$ & $\begin{array}{l}\text { Letenneur et al. (2008) and } \\
\text { Lövheim et al. (2015) }\end{array}$ \\
\hline $\begin{array}{l}\text { HSV1-infected cell cultures produce hyper- } \\
\text { phosphorylated tau. }\end{array}$ & Zambrano et al. (2008) \\
\hline $\begin{array}{l}\text { Genetic links between HSV1 and host cells from } \\
\text { GWAS. }\end{array}$ & $\begin{array}{l}\text { Licastro et al. (2011), } \\
\text { Carter (2013) }\end{array}$ \\
\hline $\begin{array}{l}\text { A } \beta \text { inhibits HSV1 DNA replication in cultured } \\
\text { neuronal cells. }\end{array}$ & Bourgade et al. (2015) \\
\hline $\begin{array}{l}\text { HSV1 causes synaptic dysfunction if cultured } \\
\text { cortical neurons. }\end{array}$ & Piacentini et al. (2015) \\
\hline $\begin{array}{l}\text { Lysosomal load increases and lysosomal function } \\
\text { inpaired in HSV1-infected cell cultures. }\end{array}$ & Kristen et al. (2018) \\
\hline $\begin{array}{l}\text { HSV1-infection confers a risk of senile dementia } \\
\text { and antiherpes antivirals strongly protect } \\
\text { against SD. }\end{array}$ & Tzeng et al. (2018a) \\
\hline $\begin{array}{l}\text { High levels of HHV6 and } 7 \text { in AD brains HSV1\& } \\
\text { also HSV1, and they cause changes in several } \\
\text { transcriptional regulators. }\end{array}$ & Readhead et al. (2018) \\
\hline $\begin{array}{l}\text { A } \beta \text { fibrillization occurs when } A \beta \text { oligomer enfolds } \\
\text { HSV1 as a protective measure. }\end{array}$ & Eimer et al. (2018) \\
\hline
\end{tabular}

and IgM indicates HSV1 recent reactivation). The results showed an association between systemic infections and cognitive decline, with HSV1 particularly implicated, and many authors explicitly stating that their results supported a viral role in $\mathrm{AD}$.

However, two recent articles (Olsson et al., 2016; Pisa et al., 2017) maintained that HSV1 is present in only a small proportion of brains of elderly people and AD patients. In the former study, the reason was probably usage of old fixed material, long duration of storage-known to be detrimental to PCR. However, in neither study did the authors specify the sensitivity of their PCR, so the level in some of their brain samples might well have been below their detection limit. The main topic of the other study was a search for fungi in brain; the authors stated that they detected HSV1 DNA in only 1 out of 10 brain samples (Pisa et al., 2017). However, as in the Olsson et al. (2016) study, the authors did not state the sensitivity of detection, and no recovery experiments were described, i.e., addition of HSV1 DNA to samples that were apparently virus DNA-negative to find if any contaminant was interfering with detection of the viral DNA. The second study sought also specific HSV1 proteins by immunohistochemistry (IHC), using fixed brain slices, and HSV1-infected HeLa cell cultures as "controls." However, the level of virus and viral proteins in human brain would have been vastly less than in the infected cell cultures-so unsurprisingly, their IHC results were negative.

Another aspect linking HSV1 to AD, and relating also to the degradation of $A \beta$, is lysosomal impairment, which many studies have shown contributes to neurodegeneration, neurons being particularly susceptible to lysosomal damage. Very recently,
Kristen et al. (2018) found that in cell cultures, HSV1 infection and also oxidative stress (OS) increased lysosomal load and impaired lysosomal function, the impairment including a reduced activity of lysosomal hydrolases and cathepsins, and in the case of OS, effects on the maturation of the cathepsins. Such changes could account for the accumulation of lysosomes and decreased functionality of lysosomal proteins, which are known to occur early in the development of AD. The authors pointed out that several polymorphisms associated with $\mathrm{AD}$, such as APOE, ABCA7, CD2AP and Phosphatidylinositol Binding Clathrin Assembly Protein (PICALM) are associated also with the HSV1 life cycle, and that some of these lead to abnormalities in autophagy. All these data support the involvement of lysosomal damage in the development of $\mathrm{AD}$, resulting in inefficient removal of toxic substances from cells, and they support the role of HSV1 in AD. The fact that the concentration of lysosomal proteins is known to be higher in $\mathrm{AD}$ patients' brains and CSF might reflect attempts by cells to rectify the impairment of the lysosomal system.

Two other very recent publications which are consistent with the viral concept of $\mathrm{AD}$ have elicited much interest and publicity, resulting in some previously sceptical opponents of the viral concept conceding some possibility of its validity. The first, by Readhead et al. (2018), analyzed the transcriptomes of brain samples from AD patients and controls, using four independent cohorts from different geographical regions of the USA. They found that herpesviruses $6 \mathrm{~A}$ and 7 , and also HSV1, were present in elderly and AD brains, the levels of HHV6 and HHV7 being significantly higher in the AD samples than in the controls, in three of the four cohorts. Their results substantiate and augment earlier studies detecting HHV6 (Lin et al., 2002) and HSV1 (Jamieson et al., 1991) in elderly brains (which revealed a similar frequency of HSV1 in brain of AD patients and controls but a much higher HHV6 frequency in patients (see also review, Hogestyn et al., 2018). Readhead et al. (2018) found also an association of virus levels with clinical dementia rating, neurofibrillary tangle density and amyloid plaque density. Plaque size too was affected by virus presence, as they showed by suppressing the gene for miR-155, a neuroprotective micro RNA: miR-155 knockout mice were crossed with APP/PS1 mice and it was found that the progeny had more and larger plaques than the APP/PS1 controls. Importantly, their analysis of protein and mRNA levels suggested that infection with these viruses causes changes in several transcriptional regulators (including several regulators of APP processing and $\mathrm{AD}$ risk-associated genes such as gamma-secretase subunit presenilin-1 (PSEN1), BACE1, Clusterin (CLU), PICALM. These data too are consistent with earlier studies using GWAS on associations between microbes, particularly herpesviruses, and $\mathrm{AD}$, as described by Licastro et al. (2011) and Carter (2013). Lin et al. (2002) raised the possibility that HHV6 infection might be merely an opportunistic infection, but suggested that it was more likely that HHV6 acts in concert with HSV1, as studies by others had shown that HHV6 augments the damage caused by other viruses in animal tissue and in cell cultures. Also, the data of Readhead et al. (2018) argue against HHV6 and HHV7 being merely opportunistic 
infections, in that they reveal association between virus levels and levels of various characteristic AD features, as mentioned above.

The second article, by Eimer et al. (2018), extends greatly previous antimicrobial research by the group, and by Bourgade et al. (2015) specifically on the antiviral properties of $A \beta$, the deposition of which they describe as an innate immune response to infection. The authors found that HSV1 and HHV6 can induce amyloid plaque production in infected mice within $24-48 \mathrm{~h}$, and that $\mathrm{A} \beta$ oligomers inhibit HSV1 infection in 3-D human neural cell culture models, and protect 5XFAD transgenic mice from acute viral encephalitis. They showed also that Abeta, probably in the form of a soluble oligomer, ensnares the virus through its heparin-binding domain via the viral envelope glycoproteins, thereby protecting brain cells from infection; fibrilization of the amyloid cloak occurs rapidly. This cloaking echoes the suggestion by Robinson and Bishop (2002) that amyloid acts protectively by entombing pathogens-a then heretical notion that was either ignored or derided. Cloaking is consistent also with the finding that in AD brains, HSV1 DNA is very specifically located within amyloid plaques (Wozniak et al., 2009a).

Both sets of authors acknowledge that their very interesting data show association of herpesvirus with $\mathrm{AD}$ but cannot prove causality. In contrast, and very importantly from the viewpoint of AD patients especially, population studies in Taiwan published in the last 12 months do provide evidence of causality.

\section{EVIDENCE FROM POPULATION EPIDEMIOLOGICAL STUDIES FOR A ROLE OF HSV1 AND OTHER HERPES VIRUSES IN DEMENTIA}

Three very significant publications have appeared in the current year, all providing data on the health and illnesses of a population over several years-information which is not available in the $\mathrm{UK}^{1}$ nor, probably, in most other countries. In Taiwan, there are records of over $99 \%$ of the population and it seems that the data are being exhaustively mined by Taiwanese epidemiologists for links between, for example, various viruses, and certain chronic disorders, including senile dementia (SD). These are yielding important results. All three articles describe data on herpes virus infections - a family of viruses that affects the vast majority of people worldwide, at least by the age of 60 or so. These viruses, once in the body, are harbored there for life, usually in a latent state but can be reactivated to an active, replicative state. Only a certain proportion of those infected actually show overt symptoms; the remainder are asymptomatic (as is the case for many or perhaps all microbial diseases). In the Taiwan publications, the word "infection" is used to denote people who showed overt signs of the disease such as shingles or recurrent cold sores or genital sores, rather than for all those who carry the virus asymptomatically in either a latent or an active, productive

\footnotetext{
${ }^{1}$ The present author sought relevant population information on HSV1, antiviral usage and $\mathrm{AD}$ in the $\mathrm{UK}$ in the 1990s but it was not available.
}

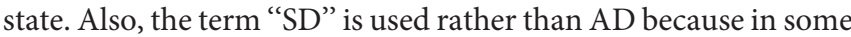
cases the diagnosis was uncertain.

Two of the articles investigated varicella zoster virus (VZV) infection in relation to long-term neurocognitive changes and the development of dementia. VZV causes chicken pox, but after acute infection it remains in the body lifelong in latent form, and in some people in older age it reactivates, causing shingles, which both sets of authors referred to as herpes zoster (HZ) and the virus as HZV. The first article, by Tsai et al. (2017), investigated 846 patients (mean age 62.2 years) who were diagnosed with $\mathrm{HZ}$ ophthalmicus (HZO) in 2005 and who developed dementia in the following 5 years. The development of dementia was compared with that of an age-matched control group of 2,538 subjects during the same 5-year period. The percentage of patients with HZO who developed SD was $4.16 \%$, whereas that of the controls was only $1.65 \%(P<0.001)$, and the crude hazard ratio of developing SD within 5 years of $\mathrm{HZO}$ diagnosis was calculated to be 2.97 after adjustment for patients' characteristics and co-morbidities. This represents a remarkably high risk of developing dementia amongst $\mathrm{HZO}$ sufferers.

In the second article, by Chen et al. (2018), 39,205 patients with HZV, age range 54-90, were diagnosed during the period 1997-2013 and were followed over an average period of 6.2 years. The incidence of dementia was compared with that of 39,205 controls (mean age of both groups was 63.5 years). The hazard ratio was only very small, namely, 1.11. A possible explanation for this marked difference from the HZO results is that in $\mathrm{HZO}$ the virus is more likely to enter the brain and cause damage there than in HZV infection. However, HZ patients who were treated with antiherpes antivirals-acyclovir, valacyclovir, tromantadine, famciclovir-showed a dramatic decrease in incidence of dementia to about a half of that in the untreated group, adjusted HR, 0.55; 95\% CI, 0.40-0.77, $(P<0.0001)$.

The third and most striking article, and the one directly relevant to HSV1 and AD was by Tzeng et al. (2018a). The authors investigated 8,362 subjects aged 50 years or over during the year 2000 who were newly diagnosed with HSV1 or HSV2 infections-presumably recurrent herpes labialis or genital ulceration, on at least three outpatient visits within the year. The control group of 25,086 age- and gender-matched subjects had no HSV infection during the year 2000. The incidence of dementia in both groups was investigated during the 10 years 2001-2010. The risk of developing SD in the HSV group was found to be 2.56fold greater, 95\% CI 2.351-2.795; $P<0.001$ ), similar to the risk associated with ophthalmic HZO infection. The main effect was seen in those with HSV1 rather than HSV2 infections. Subtypes $\mathrm{AD}$ and vascular dementia had similar risk profiles.

Even more strikingly, a group of HSV-infected patients $(N=7,215)$ who had been treated with one of various anti-herpes agents (acyclovir, famciclovir, ganciclovir, idoxuridine, penciclovir, tromantadine, valaciclovir (VCV-the biodrug of ACV, which is better absorbed) and valganciclovir), showed a dramatic reduction of almost 10 fold in the later incidence of SD compared with those who received no treatment $(N=1,147$; relative risk factor $=0.092,95 \%$ CI $0.079-0.108, P<0.001)$. In the 
subgroup with antiherpetic medications, 419 (5.80\%) developed dementia in the longitudinal follow-up within 10 years. In the subgroup without antiherpetic medication treatment, 325 (28.33\%) developed dementia in the same follow-up period; relative risk factor $=0.092,95 \%$ CI $0.079-0.108(P<0.001)$.

Thus, antiherpetic medications, either over-all (adjusted HR: $0.092,0.079-0.108, p<0.001$ ) or individual antivirals, were associated with decreased risk of developing dementia (Table 3). The protection was greater in those treated for longer time periods (over 30 days vs. less than 30 days) but the effect is remarkable anyway in showing that treatment for periods of relatively short duration could prevent the (presumably) later processes in brain which ultimately led to the development of $\mathrm{AD}$. In the case of $\mathrm{HZ}$ patients, whether the antiviral treatment acted directly against HZV action if in brain, or against HSV1 reactivated in brain by HZ-induced inflammation is unknown; the latter seems more likely in view of the fact that HZV DNA has not been detected in any elderly or AD brains (Lin et al., 1997). In theory (though probably not in practice), a direct effect of any microbe in brain as opposed to an effect of HSV1 reactivated by microbe-induced inflammation could be tested by treatment with an antiviral that targets only HSV1, but current antiherpetics are not HSV1-specific, and anyway, such treatment might be ethically dubious.

The mechanism of this action is unknown. To speculate, it might involve prevention by anti-viral treatment (AVT) of the virus reaching the CNS-based on the assumption that this passage occurs in middle age, when the immune system starts to decline. This seems plausible as all the subjects with HSV1 infection were $\geq 50$ years old and were selected on the basis of having had newly diagnosed HSV1 infection during the period January 1, 2000 to December 31, 2000. The virus might not therefore have reached their brain, as although primary infection must have occurred before the diagnosis-and possibly much earlier (for in some cases overt symptoms occur well after primary infection), the virus level might have been too low to lead to passage to the brain. AVT, which stops HSV1 replication, would have reduced the level in the periphery, thereby decreasing

TABLE 3 | Relative risks for development of senile dementia in herpes zoster and HSV cases, and after anti-viral treatment.

\begin{tabular}{lc}
\hline Type of illness/infection & $\begin{array}{c}\text { Relative } \\
\text { risk }\end{array}$ \\
\hline
\end{tabular}

\section{Herpes zoster ophthalmicus}

Developing SD within 5 years of $\mathrm{HZO}$ diagnosis vs. age-matched controls.

Herpes zoster

Developing SD within 6 years of $\mathrm{HZ}$ diagnosis vs. age-matched controls.

Developing SD in AVT-treated $\mathrm{HZ}$ patients vs. untreated $\mathrm{HZ}$ patients

\section{Herpes simplex types 1 and $2^{*}$}

Developing SD within 10 years of HSV diagnosis vs. HSV-negative subjects.

Developing SD in AVT-treated HSV patients vs. untreated HSV patients.

*All severe cases. the chance of its reaching the brain. However, it seems likely that AVT, rather than blocking viral passage, probably delayed it. This could be checked by extending the survey further, perhaps from 2010 to 2017, to find if the number of dementia cases increased (though there would be an increase also in death rate with age). Investigations post mortem to seek HSV1 DNA in the brain of any such subsequent cases of dementia, and in some of those who remained free of the disease, might help to clarify the effect of AVT.

All these data, together with the data on HSV1 presence in a high proportion of elderly brains (Jamieson et al., 1991), and its association with APOE- $\varepsilon 4$ in AD patients (Itzhaki et al., 1997), strongly support a causal role of HSV1 in AD, and support also the likelihood that antiherpetic treatment-probably more effective if combined with anti-inflammatory treatment-could be used to prevent disease occurrence or to slow disease progression. However, there are no data on the effect of antivirals on those already suffering the disease. Indeed, the fact that antiviral treatment was very effective in reducing the incidence of dementia, when given before any overt signs of dementia were apparent, suggests that treatment to prevent the disease would be more likely to succeed if carried out before middle age (say between $\sim 30-40$ years), even if the treatment were for only a relatively short period, rather than if given after the onset of $\mathrm{AD}$. In the UK, the proportion of $30-40$ year old group who are HSV1-seropositive is at most $\sim 70 \%$ (Looker et al., 2015), and the proportion of that age-group who are carriers of an APOE- $\varepsilon 4$ allele is $\sim 25 \%$, so overall, only approximately $18 \%(0.7 \times 25 \%)$ of the age group would be most at risk and therefore most likely to benefit from antiviral treatment, which, it should be noted, is very safe and relatively inexpensive.

Another uncertainty exists because the treated group comprised only those who had severe herpes labialis or severe genital ulcers (as they were selected only if they had made at least three outpatient visits in the year 2000). What proportion these severe cases constituted of those who eventually developed dementia and were HSV1-seropositive and APOE- $\varepsilon 4$ carriers, is uncertain, though it is probably very low. Thus, it is unknown if subjects who are HSV1-seropositive and APOE- $\varepsilon 4$ carriers, but who are only mildly affected or are asymptomatic, would be as susceptible to treatment. Nonetheless, it seems extremely likely that the results of the Taiwanese studies would apply also to the many AD patients who, although HSV1seropositve, never previously displayed overt symptoms of the infection.

Despite the uncertainties mentioned above, as well as others such as what future modes and timing of treatment should be used, these epidemiological results represent a very important new step to the problem of understanding and treating those AD cases probably caused by HSV1 (Itzhaki and Lathe, 2018). It is worth stressing though that these data and the preceding evidence for a role of HSV1 in AD, do not preclude a role for bacteria, in particular, Borrelia, Chlamydia pneumoniae, and some oral bacteria, which are probably the microbes most strongly implicated in AD (see review, Miklossy and McGeer, 2016): one or more such microbes might be involved, leading 
to the disease in the sizeable proportion of $\mathrm{AD}$ patients whose illness is not accounted for by HSV1 (in combination with APOE- $\varepsilon 4$ ).

\section{RECENT DATA FROM OTHER DISEASES RELEVANT TO HSV1 AND COGNITIVE DECLINE AND TO ANTI-VIRAL TREATMENT}

Three other publications are particularly interesting, even though none deals directly with the issue of HSV1 in brain and AD. The first relates to certain cognitive features and HSV1. A number of studies have shown that HSV1-seropositivity is associated with cognitive dysfunction-particularly in schizophrenic (SZ) patients. Bhatia et al. (2017) investigated temporal changes in various cognitive features over a period of $1-3$ years, mean follow-up time 1.93 years, and also the effect of VCV, comparing the changes in HSV1 seropositive and seronegative SZ and control subjects. Emotion Identification and Discrimination (EMOD), spatial memory and spatial ability were investigated in 131 HSV1-seropositive and 95 HSV1-seronegative people, mean ages 35 and 32, respectively. EMOD was defined as ability to discriminate between emotions and is considered an important component of social cognition (Gur et al., 2010).

SZ subjects had significantly lower scores in all cognitive domains. The HSV1-infected subjects had significantly lower scores than uninfected subjects for the above cognitive features, regardless of SZ diagnosis ( $p=0.025,0.029,0.046$, respectively, and their values for EMOD decreased significantly more rapidly $(p=0.033)$.

In the VCV study, 30 subjects were given VCV orally at $1.5 \mathrm{gm}$ twice daily for 16 weeks, and 32 subjects were given placebo, while continuing with standard antipsychotic treatment. The results indicated improvement in EMOD among HSV1 infected persons with SZ, following VCV treatment ( $p=0.048$, Cohen's $d=0.43$ ). The authors concluded that HSV1 infection was associated with dysfunction in various cognitive features at study entry in SZ patients and controls, and with greater temporal decline in EMOD.

Another interesting study investigated fibromyalgia (FM) in relation to HSV1. FM is characterized by chronic widespread pain, fatigue, sleep disruption, and cognitive impairment. Pridgen et al. (2017) treated patients with the antiherpetic famciclovir (FCV), a nucleoside analog, in combination with a Cox-2 inhibitor, celecoxib (combination referred to as IMC-1), in a multicenter trial. Usage of the anti-herpes antiviral agent was based on the hypothesis that the disorder is caused by intermittent reactivation of latent HSV1 because of stress, etc. Celecoxib was used not only because of its direct Cox- 2 inhibition but also because it has anti-herpes action. Several herpes viruses, including HSV-1, are known to upregulate COX-2 (Liu et al., 2014), and virally induced upregulation of COX enzymes is important for efficient HSV-1 replication. COX-2 inhibition reduces the severity of primary herpes virus lesions and inhibits reactivation of latent infections (Higaki et al., 2009). FM patients, mainly caucasian and female, age range 18-70 years, were enrolled in a 16-week, double-blinded, placebo-controlled, proof-of-concept trial held in 12 centers. Randomized patients received either IMC-1 or placebo. Fifty-seven patients completed the 16-week course of treatment with IMC-1 and 45 patients received a placebo (mean ages 51 and 48 years, respectively). The outcome was assessed by standard ratings of pain, fatigue and depression at baseline and weeks 6, 12 and 16 of the study.

The data showed a significant decrease in FM-related pain in IMC-1-treated patients compared with those given the placebo. The safety and tolerability profile for IMC-1 were encouraging. The authors commented that the two drugs when used in combination, might have acted additively and/or synergistically, thereby increasing the efficacy. Previous investigators using them separately had found that in contrast neither drug alone was efficacious in the treatment of FM. They concluded that their results supported the hypothesis that herpes virus infections may contribute to this syndrome.

The third article concerns FM and dementia, pursued by Taiwanese investigators again using the country's insurance data, the rationale being that inflammation-related diseases or other pain disorders, such as headaches, have been shown to be associated with increased risk of dementia. Tzeng et al. (2018b) investigated 41,612 subjects with FM diagnosed between January 1, and December 31, 2000, and 124,836 controls without FM, matched for age, sex and index year. All subjects were aged 50 years or over. Patients were selected on the basis of having made at least three outpatient visits within the 1-year study period for FM or other co-morbidity. The risk of developing dementia during the 10-year follow-up period to December 31, 2010, was investigated. The results showed that FM was associated with increased risk of all types of dementia: 1,704 of the 41,612 FM patients (21.23 per 1,000 person-years) developed dementia, compared with 4,419 of the 124,836 controls (18.94 per 1,000 person-years). After adjustment for sex, age, etc. the hazard ratio was calculated to be 2.77 (95\% CI: 2.61-2.95, $P<0.001)$. For the individual types of dementia, the risk for $\mathrm{AD}$ was 3.35-fold, for non-vascular dementia 3.14-fold (a group which, they acknowledge, might have included some wrongly diagnosed $\mathrm{AD}$ patients), and for vascular dementia 2.72-fold.

Tzeng et al. (2018b) described several possible limitations, and therefore concluded that the findings suggest association of FM with dementia, rather than causation, and that a longer follow-up period would help to clarify the long-term risks. However, in view of the study by Pridgen et al. (2017) suggesting that herpes virus infections may contribute to FM, the linking factor-and probable causative agent-is HSV1.

\section{HSV1 INFECTION OF MICE}

Although there is increasing evidence in humans that long term HSV latency correlates with increased risk of neurodegenerative disease, few animal studies have focused on correlating long term HSV infection in the CNS with functional cognitive/behavioral endpoints. Beers et al. (1995) published the first report providing evidence that spatial memory deficits were associated with HSV infection in Lewis rats that had recovered from encephalitis; 
this study was performed relatively soon after recovery from primary infection and long-term effects were not evaluated. An ongoing study is investigating whether long term-HSV latency results in measurable differences in cognitive performance in human-APOE- $\varepsilon 4$ targeted knock-in transgenic mice (huApoE4; Sawtell et al., 2018). In two independent studies, two groups of mock infected and two groups of HSV-1 17syn + infected (via the ocular route) huApoE4 mice were utilized. Mice were monitored for overall health status, including weight, during the entire study. With the exception of minor blepharitis during acute stage of infection, no differences in overall health status between mock and HSV-1 infected groups were observed. Signs of encephalitis were not observed during acute infection and mortality from viral infection did not occur. HSV latency in the trigeminal ganglia and throughout the CNS was demonstrated at 40 days post infection by real-time qPCR. At 12 months post infection, groups of mice ( $n \geq 16$ /group) were evaluated in a number of tests including the Morris Water Maize (MWM) which tests hippocampus-dependent spatial learning and memory. Striking and significant differences in both studies between HSV infected and mock infected groups were observed in the MWM, suggesting alteration in hippocampal function. Examination of hippocampal region revealed an $\sim 8$-fold increase in focal $A \beta$ deposits. The investigators conclude that these behavioral studies draw a solid link between long term HSV latent infection and cognitive impairment in the context of the huApoE4 allele.

\section{LINKS AMONG EPILEPSY AND AD, APOE, HHV6, HSV1 AND HERPES SIMPLEX ENCEPHALITIS (HSE)}

Increasing numbers of publications are linking epilepsy and $\mathrm{AD}$ in showing that seizure-like activity in the brain is associated with some of the cognitive decline seen in $\mathrm{AD}$ patients, and that seizures are more common in $\mathrm{AD}$ than in the general population. Also, the risk factors, APOE- $\varepsilon 4$, HSV1 or HHV6 are increasingly implicated in both disorders. The three latter factors are discussed below.

$\mathrm{AD}$ patients have an increased risk of epilepsy and almost $50 \%$ have abnormal electrical activity in the brain, which does not cause a seizure but is detectable by brain scan technology. Lam et al. (2017) pointed out that amyloid plaques, characteristic of $\mathrm{AD}$ in their numbers in brain, were first described in 1892, in patients with epilepsy, and that $\mathrm{AD}$ and epilepsy both impair cognition and show overlapping patterns of cellular neurodegeneration and hypometabolism in the temporal lobe. They added that interneurons are among the first to die in $\mathrm{AD}$ mesial temporal cortex and that the ensuing degradation of synaptic connectivity and circuit remodeling could contribute to memory storage and retrieval. Intermittent temporal lobe dysrythmia could therefore account for early fluctuations in cognition in $\mathrm{AD}$ patients. The authors investigated mesial temporal activity in two $\mathrm{AD}$ patients with fluctuating cognition but with no previous history of seizures, using intracranial foramen ovale electrodes, and detected clinically silent hippocampal seizures and epileptiform spikes during sleep, a period when both were most likely to interfere with memory consolidation. They suggested that early development of occult hippocampal hyperexcitability might contribute to the pathogenesis of AD.

In a recent feasibility study (Musaeus et al., 2017), an anti-epileptic drug was tested for its potential impact on the brain activity of patients with mild AD in a double-blind withinsubject study. Seven patients were investigated on three separate occasions: their baseline EEG was examined and then they were injected with either a placebo or with the anti-seizure drug levetiracetam, at either a low dose $(2.5 \mathrm{mg} / \mathrm{kg})$ or a higher dose $(7.5 \mathrm{mg} / \mathrm{kg})$. Each patient eventually got one dose of each type, in random order. After injection, patients underwent magnetic resonance imaging (MRI) to measure blood flow in the brain to quantify brain activity and detect its location in the brain, and they took standard cognitive tests for memory, executive functioning, naming, visuospatial ability and semantic function, all of which are affected in $\mathrm{AD}$. The higher doses of the anti-seizure drug were found to normalize abnormalities in the patients' EEG profiles, increasing brain wave frequencies that had been abnormally low, and decreasing those that had been abnormally high. Although the authors found no improvement in cognitive function after a single dose of medication, they plan a longer and larger study.

There is also an amyloid connection between epilepsy and AD: Joutsa et al. (2017) investigated 41 people who had suffered childhood-onset epilepsy (one in a hundred develop the disorder before age 18), and were then followed for 50 years until late middle age, and 46 matched population-based controls, using positron emission tomography scanning. The aim was to find if there was a predisposition to development of progressive neurodegenerative disorders such as $\mathrm{AD}$, as indicated by $\mathrm{A} \beta$ accumulation, and to find if APOE genotype is a factor. The authors reported that the middle-aged adults who had developed childhood epilepsy had more amyloid plaques in their brains than matched controls without epilepsy. Plaque accumulation was especially great in APOE- 44 carriers. The subjects had had a variety of different epilepsy syndromes and were in remission. Many had not had anti-epileptic drug therapy for decades which, the authors suggested, linked the increased brain $A \beta$ to the pathophysiology of epilepsy rather than to seizure control or duration of active epilepsy, and might help to explain why childhood epilepsy could lead to cognitive disorders such as AD.

There have been a number of studies specifically on the involvement of APOE, and also of HSV1 and HHV6, in epilepsy. The role of APOE in epilepsy development is still controversial, some studies showing that ApoE- $\varepsilon 4$ is associated with an increased risk of medically refractory epilepsy, of late post-traumatic seizures and of non-lesional mesial temporal lobe epilepsy (MTLE), while other studies found no association in non-lesional TLE patients nor in MTLE with hippocampal sclerosis (MTLE-HS) patients (Leal et al., 2017). An association between this isoform and age of onset of temporal lobe epilepsy was found in several studies; also, the APOE- $\varepsilon 4$ allele has been associated with cognitive impairment in epileptic patients. Leal et al. (2017) aimed to elucidate the importance 
of febrile seizures (FS) and the role of APOE in MTLE-HS development. They described MTLE with hippocampal sclerosis (MTLE-HS) as the most frequent pharmaco-resistant epilepsy, with most HS patients having suffered CNS infection, head or birth trauma or FS, the latter being the most common injury. Their results showed no differences in APOE- $\varepsilon 4$ frequencies between MTLE-HS patients and controls or between MTLE-HS subgroups, but APOE- $\varepsilon 4$ carriers had an earlier MTLE-HS onset, as did MTLE-HS patients with FS antecedents compared with non-FS antecedents. They concluded that although APOE- $\varepsilon 4$ and FS might not be involved in aetiopathogenic mechanisms of MTLE-HS, these factors could speed up disease development in predisposed individuals.

Other mainly negative findings included that of Li et al. (2016) who investigated Han Chinese and found no association between APOE- $\varepsilon 4$ carriage and the age of onset, duration of epilepsy, frequency of seizure, febrile convulsion history, or hippocampal sclerosis, although they suggested that the $\varepsilon 4$ allele was a possible risk factor for non-lesional MTLE. Also, Lavenex et al. (2016) detected no association between APOE polymorphisms and FS.

As to a viral involvement in epilepsy, Wipfler et al. (2018) carried out a meta analysis of eight publications on HHV6 and MTLE, all of which had used surgically removed tissue samples from pharmaco-resistant patients. HHV-6 DNA was detected in brain of $19.6 \%$ of all MTLE patients compared to $10.3 \%$ of all controls $(p>0.05)$. As the authors state, these data indicate an association between HHV-6 DNA and MTLE, although whether it involves HHV6 types A or B or both is unknown, as also is whether the association is causal.

HSE causes epilepsy and epilepsy surgery causes HSE recurrence. HSE is caused by HSV1 and is the most common type of viral encephalitis. It is an acute, rare but often fatal disease of the brain. In the last few decades, treatment of HSE by ACV and other antivirals has decreased mortality, but morbidity in survivors is still high. In the author's previous review (Itzhaki, 2017), it was pointed out that HSE is a major cause of seizures, the occurrence of which is probably underestimated because of their frequent subtlety. Unprovoked seizures often occur in the post-acute phase (21 days from onset of initial symptoms) and they resist treatment. If seizures occur during the acute phase, there is a greater risk of post-encephalitic epilepsy, and hence of poor long- term prognosis (Sellner and Trinka, 2012).

In a reverse effect, surgery for treatment of epilepsy can cause the relapse of HSE, as described in several case reports: Bourgeois et al. (1999), Kim et al. (2013), Uda et al. (2013), Lo Presti et al. (2015), de Almeida et al. (2015) and Alonso-Vanegas et al. (2016). HSE relapse presumably occurs because of reactivation of existing HSV1 DNA in the brain caused by axonal cutting-a known reactivator of the virus.

HSE has some links with $\mathrm{AD}$, in that it leads not only to seizures but also to memory deficits and behavioral changes, resembling some of the changes seen in $\mathrm{AD}$ patients. Thus, there are functional inks between HSE sequelae and AD, links between $\mathrm{AD}$ and epilepsy, and HSE and epilepsy, probable links between epilepsy and herpes viruses, possible links of epilepsy also with specific APOE alleles, and much evidence linking HSV1 to AD. The episodes of HSV1 reactivation which are postulated to occur in brain of the elderly must necessarily be very limited in extent as otherwise, they would lead to overt encephalitis. In view of these connections, it seemed reasonable to consider that HSE occurrence in APOE- $\varepsilon 4$ carriers might lead to AD, although it would be rare because of the rarity of HSE (approx 1-3 cases per million population). Relevant literature was therefore searched to find if people who had suffered from HSE have a greater risk of developing age-related cognitive decline, and specifically of dementia or AD. Four published studies and one unpublished survey showed an increase in dementia or, specifically, of $\mathrm{AD}$, amongst survivors of HSE, suggesting that the survivors might have shared another characteristic which added to a risk conferred by HSE-possibly, an APOE- 44 allele, but unfortunately, none of the studies investigated the APOE genotype of their subjects (Itzhaki and Tabet, 2017).

There appear to be only two publications on APOE genotypes of HSE patients, one of which implicated APOE- $\varepsilon 2$ as a risk (Lin et al., 2001). This would not necessarily invalidate the APOE$\varepsilon 4$ hypothesis, as AD might develop mainly in those HSE patients (some half of the total) who are not APOE- $\varepsilon 2$ carriers. However, a second study found no significant difference between HSE patients' genotypes and those of controls (Nicoll et al., 2001). The reason for the difference is unknown. As to dementia occurring also amongst survivors of non-HSE encephalitis (caused by other herpesviruses, bacteria or parasites), possibly this is a consequence of encephalitic damage in the CNS, which might well cause reactivation of latent HSV1 if present.

\section{TREATMENT OF HSE WITH ACYCLOVIR AND RELEVANCE TO THE TREATMENT OF HSV1-SEROPOSITIVE, APOE- $\varepsilon 4$ AD PATIENTS}

The standard treatment for HSE is intravenous acyclovir, following trials in the 1980s which assessed its efficacy. It is strongly recommended that ACV should be given as soon as possible during an attack (or even before the diagnosis is certain, in suspected cases) because its usage leads to a striking drop in mortality. However, all too often there are serious sequelae of the illness, as mentioned above. As to the efficacy of longer-term treatment than the standard 14-21 days, a clinical trial of neonates with "HSV disease with CNS involvement" showed that prolonged oral dosing of ACV for 6 months after the usual 14-21 days greatly improved neurological outcomes (Kimberlin et al., 2011). However, another study found, in contrast, that valacyclovir treatment given for 90 days after standard intravenous ACV did not benefit adult HSE patients (Gnann et al., 2015; who were given $2 \mathrm{~g}$ thrice daily or placebo tablets).The primary endpoint was survival, with no or mild neuropsychological impairment at 12 months, as measured by the Mini-Mental State Examination (MMSE), and the Mattis Dementia Rating Scale (MDRS). To explain this unexpected result, Tyler (2015) pointed out that the patients in the study by Gnann et al. (2015) were a select group, described by him as a relatively high-functioning subset of HSE survivors. No seriously ill 
patients were enrolled, so whether such patients or those with associated immuno-compromising conditions might have benefitted is unknown. Nonetheless, the patients in the adult trial, treated and untreated, showed a remarkable extent of recovery. By 2 years post-illness, some $90 \%$ of the subjects had no or only mild impairment, as judged by either of the score systems. In fact, most of the improvement occurred within the first 90 days.

This high recovery group represents probably only a small minority: Gnann and Whitley (2017) have estimated that only $40 \%-55 \%$ of sufferers are able to resume activities of daily living at 12 months. To improve the high morbidity, they suggest the usage of combinations of ACV-or VCV plus immunomodulatory drugs to reduce ongoing inflammation. A major possibility would be treatment with the combination IMC-1 used by Pridgen et al. (2017; see above).

As to the effects of treating $\mathrm{AD}$ patients long term, ACV causes few side-effects except in renally impaired patients; these should therefore be excluded from relevant trials. No ill effects were seen when VCV was used for a 2 year period at a dosage of 3 g per day, in a clinical trial designed to investigate its efficacy in treating multiple sclerosis (Friedman et al., 2005) and Pridgen et al. (2017) found the safety and tolerability of their IMC-1 in the 4-month treatment of their patients to be satisfactory.

\section{CONCLUSIONS}

Further population epidemiological work would be invaluable for understanding the role of microbes, in particular HSV1, in AD. Using the Taiwan records, or those of any other country with comparable information, the subsequent development of dementia amongst subjects who had suffered mild herpes labialis or genital herpes could be investigated, although they would be far less likely to be documented, and therefore much less

\section{REFERENCES}

Agostini, S., Mancuso, R., Baglio, F., Cabinio, M., Hernis, A., Costa, A. S., et al. (2016). High avidity HSV-1 antibodies correlate with absence of amnestic mild cognitive impairment conversion to Alzheimer's disease. Brain Behav. Immun. 58, 254-260. doi: 10.1016/j.bbi.2016.07.153

Alonso-Vanegas, M. A., Quintero-López, E., Martínez-Albarrán, A. A., and Moreira- Holguín, J. C. (2016). Recurrent herpes simplex virus encephalitis after neurologic surgery. World Neurosurg. 89, 731.e1-731.e5. doi: 10.1016/j. wneu.2016.01.057

Alvarez, G., Aldudo, J., Alonso, M., Santana, S., and Valdivieso, F. (2012). Herpes simplex virus type 1 induces nuclear accumulation of hyperphosphorylated tau in neuronal cells. J. Neurosci. Res. 90, 1020-1029. doi: 10.1002/jnr. 23003

Beers, D. R., Henkel, J. S., Kesner, R. P., and Stroop, W. G. (1995). Spatial recognition memory deficits without notable CNS pathology in rats following herpes simplex encephalitis. J. Neurol. Sci. 131, 119-127. doi: 10.1016/0022510x(95)00099-n

Bhatia, T., Wood, J., Iyengar, S., Narayanan, S. S., Beniwal, R. P., Prasad, K. M., et al. (2017). Emotion discrimination in humans: its association with HSV-1 infection and its improvement with antiviral treatment. Schizophr. Res. 193, 161-167. doi: 10.1016/j.schres.2017.08.001

Bhattacharjee, P. S., Neumann, D. M., Foster, T. P., Bouhanik, S., Clement, C., Vinay, D., et al. (2008). Effect of human apolipoprotein E genotype on the pathogenesis of experimental ocular HSV-1. Exp. Eye Res. 87, 122-130. doi: 10.1016/j.exer.2008.05.007 identifiable than severe cases. However, investigation of even asymptomatic HSV-seropositive people vs. HSV-seronegative people would be informative, although by the age of 60 the latter would comprise only a very small minority. Also, individuals could be selected who had suffered severe peripheral infections, on the basis that the inflammation thus caused could lead to inflammation in the brain, and reactivation of any latent microbe there. Of particular interest would be those who had suffered HSE, and also epilepsy patients-even those in whom no virus infection had been reported. If tissue, blood, or salve samples were available, APOE genotypes could be determined for any association with other characteristics.

Clearly, the types of antiviral which might be used for treating $\mathrm{AD}$ should be carefully chosen, especially if combined with an anti-inflammatory agent, as well as the duration of treatment and stage at which their usage would most effective. Even if the effects were merely a delay in onset of the disease, this would still be enormously beneficial for patients, carers and the economy. Of course, vaccination against HSV1 would be the better option, as prevention of disease is better than cure. Unfortunately, however, there is currently no vaccine for HSV1 and any vaccine trial would presumably have to extend for many years to find the outcome.

Research data on a microbial cause of $\mathrm{AD}$ have been ignored or dismissed for three decades, very unfortunately for those who developed $\mathrm{AD}$ during that period and who therefore had no chance of benefitting from the information. Surely, now is the time to rectify the situation by determining and then using the best means of treatment at hand.

\section{AUTHOR CONTRIBUTIONS}

The author confirms being the sole contributor of this work and has approved it for publication.

Bourgade, K., Garneau, H., Giroux, G., Le Page, A. Y., Bocti, C., Dupuis, G., et al. (2015). $\beta$-amyloid peptides display protective activity against the human Alzheimer's disease-associated herpes simplex virus-1. Biogerontology 16, 85-98. doi: 10.1007/s10522-014-9538-8

Bourgeois, M., Vinikoff, L., Lellouch-Tubiana, A., and Sainte-Rose, C. (1999). Reactivation of herpes virus after surgery for epilepsy in a pediatric patient with mesial temporal sclerosis: case report. Neurosurgery 44, 633-635; discussion 635-636. doi: 10.1097/00006123-199903000-00107

Burgos, J. S., Ramirez, C., Sastre, I., and Valdivieso, F. (2006). Effect of apolipoprotein $\mathrm{E}$ on the cerebral load of latent herpes simplex virus type 1 DNA. J. Virol. 80, 5383-5387. doi: 10.1128/jvi.00006-06

Carter, C. J. (2013). Susceptibility genes are enriched in those of the herpes simplex virus $1 /$ host interactome in psychiatric and neurological disorders. Pathog. Dis. 69, 240-261. doi: 10.1111/2049-632x.12077

Chen, V. C.-H., Wu, S.-I., Huang, K.-Y., Yang, Y.-H., Kuo, T.-Y., Liang, H.-Y., et al. (2018). Herpes zoster and dementia. J. Clin. Psychiatry 79:16m11312. doi: 10.4088/JCP.16m11312

de Almeida, S. M., Crippa, A., Cruz, C., de Paola, L., de Souza, L. P., Noronha, L., et al. (2015). Reactivation of herpes simplex virus-1 following epilepsy surgery. Epilepsy Behav. Case Rep. 4, 76-78. doi: 10.1016/j.ebcr.2014.08.007

De Chiara, G., Marcocci, ME., Civitelli, L., Argnani, R., Piacentini, R., Ripoli, C., et al. (2010). APP processing induced by herpes simplex virus type 1 (HSV-1) yields several APP fragments in human and rat neuronal cells. PLoS One 5:e13989. doi: 10.1371/journal.pone.0013989

Eimer, W. A., Vijaya Kumar, D. K., Navalpur Shanmugam, N. K., Rodriguez, A. S., Mitchell, T., Washicosky, K. J., et al. (2018). Alzheimer's disease-associated 
$\beta$-amyloid is rapidly seeded by herpesviridae to protect against brain infection. Neuron 99, 56.e3-63.e3. doi: 10.1016/j.neuron.2018.06.030

Friedman, J. E., Zabriskie, J. B., Plank, C., Ablashi, D., Whitman, J., Shahan, B., et al. (2005). A randomized clinical trial of valacyclovir in multiple sclerosis. Mult. Scler. J. 11, 286-295. doi: 10.1191/1352458505ms1185oa

Gnann, J. W. Jr., Sköldenberg, B., Hart, J., Aurelius, E., Schliamser, S., Studahl, M., et al. (2015). Herpes simplex encephalitis: lack of clinical benefit of long-term valacyclovir therapy. Clin. Infect. Dis. 61, 683-691. doi: 10.1093/cid/ civ369

Gnann, J. W. Jr., and Whitley, R. J. (2017). Herpes simplex encephalitis: an update. Curr. Infect. Dis. Rep. 19:13. doi: 10.1007/s11908-017-0568-7

Gur, R. C., Richard, J., Hughett, P., Calkins, M. E., Macy, L., Bilker, W. B., et al. (2010). A cognitive neuroscience-based computerized battery for efficient measurement of individual differences: standardization and initial construct validation. J. Neurosci. Methods 187, 254-262. doi: 10.1016/j.jneumeth.2009. 11.017

Higaki, S., Watanabe, K., Itahashi, M., and Shimomura, Y. (2009). Cyclooxygenase (COX)-inhibiting drug reduces HSV-1 reactivation in the mouse eye model. Curr. Eye Res. 34, 171-176. doi: 10.1080/02713680802650377

Hogestyn, J. M., Mock, D. J., and Mayer-Proschel, M. (2018). Contributions of neurotropic human herpesviruses herpes simplex virus 1 and human herpesvirus 6 to neurodegenerative disease pathology. Neural Regen. Res. 13, 211-221. doi: 10.4103/1673-5374.226380

Ill-Raga, G., Palomer, E., Wozniak, M. A., Ramos-Fernández, E., BoschMorató, M., Tajes, M., et al. (2011). Activation of PKR causes amyloid B-peptide accumulation via de-repression of BACE1 expression. PLoS One 6:e21456. doi: 10.1371/journal.pone.0021456

Itzhaki, R. F. (2014). Herpes simplex virus type 1 and Alzheimer's disease:increasing evidence for a major role of the virus. Front. Aging Neurosci. 6:202. doi: 10.3389/fnagi.2014.00202

Itzhaki, R. F. (2017). Herpes simplex virus type 1 and Alzheimer's disease: possible mechanisms and signposts. FASEB J. 31, 3216-3226. doi: 10.1096/fj.201700360

Itzhaki, R. F., and Lathe, R. (2018). Herpes viruses and senile dementia: first population evidence for a causal link. J. Alzheimers Dis. 64, 363-366. doi: $10.3233 /$ jad-180266

Itzhaki, R. F., Lin, W.-R., Shang, D., Wilcock, G. K., Faragher, B., and Jamieson, G. A. (1997). Herpes simplex virus type 1 in brain and risk of Alzheimer's disease. Lancet 349, 241-244. doi: 10.1016/S0140-6736(96)10149-5

Itzhaki, R. F., and Tabet, N. (2017). Herpes simplex encephalitis and Alzheimer's disease: is there a link? J. Neurol. Sci. 380, 20-21. doi: 10.1016/j.jns.2017.06.046

Jamieson, G. A., Maitland, N. J., Craske, J., Wilcock, G. K., and Itzhaki, R. F. (1991). Detection of herpes simplex virus type 1 DNA sequences in normal and Alzheimer's disease brain using polymerase chain reaction. Biochem. Soc. Trans. 19:122S. doi: 10.1042/bst019122s

Jayasuriya, A. N., Itzhaki, R. F., Wozniak, M. A., Patel, R., Smit, E. J., Noone, R., et al. (2008). Apolipoprotein E- $\varepsilon 4$ and recurrent genital herpes in individuals co-infected with herpes simplex virus type 2 and HIV. Sex. Transm. Infect. 84, 516-517. doi: 10.1136/sti.2008.032367

Joutsa, J., Rinne, J. O., Hermann, B., Karrasch, M., Anttinen, A., Shinnar, S., et al. (2017). Association between childhood-onset epilepsy and amyloid burden 5 decades later. JAMA Neurol. 74, 583-590. doi: 10.1001/jamaneurol.2016.6091

Kim, S. H., Lee, S. G., Kim, S. H., Kim, D. S., and Kim, H. D. (2013). Relapsed herpes simplex virus encephalitis after epilepsy surgery. J. Epilepsy Res. 3, 28-31. doi: 10.14581/jer.13005

Kimberlin, D. W., Whitley, R. J., Wan, W., Powell, D. A., Storch, G., Ahmed, A., et al. (2011). Oral acyclovir suppression and neurodevelopment after neonatal herpes. N. Engl. J. Med. 365, 1284-1292. doi: 10.1056/NEJMoa1003509

Kristen, H., Sastre, I., Muñoz-Galdeano, T., Recuero, M., Aldudo, J., and Bullido, M. J. (2018). The lysosome system is severely impaired in a cellular model of neurodegeneration induced by HSV-1 and oxidative stress. Neurobiol. Aging 68, 5-17. doi: 10.1016/j.neurobiolaging.2018.03.025

Lam, A. D., Deck, G., Goldman, A., Eskandar, E. N., Noebels, J., and Cole, A. J. (2017). Silent hippocampal seizures and spikes identified by foramen ovale electrodes in Alzheimer's disease. Nat. Med. 23, 678-680. doi: 10.1038/ nm. 4330

Lavenex, P., Lavenex, P. B., Cachat, F., Gehri, M., and Juvet, T. (2016). No association between ApoE polymorphism and febrile seizures. Neurol. Sci. 37, 31-36. doi: 10.1007/s10072-015-2351-6
Leal, B., Chaves, J., Carvalho, C., Bettencourt, A., Freitas, J., Lopes, J., et al. (2017). Age of onset of mesial temporal lobe epilepsy with hippocampal sclerosis: the effect of apolipoprotein E and febrile seizures. Int. J. Neurosci. 127, 800-804. doi: 10.1080/00207454.2016.1264396

Letenneur, L., Pérès, K., Fleury, H., Garrigue, I., Barberger-Gateau, P., Helmer, C., et al. (2008). Seropositivity to herpes simplex virus antibodies and risk of Alzheimer's disease: a population-based cohort study. PLoS One 3:e3637. doi: 10.1371/journal.pone.0003637

Li, Z., Ding, C., Gong, X., Wang, X., and Cui, T. (2016). Apolipoprotein E $\varepsilon 4$ allele was associated with nonlesional mesial temporal lobe epilepsy in han chinese population. Medicine 95:e2894. doi: 10.1097/MD.0000000000002894

Licastro, F., Carbone, I., Ianni, M., and Porcellini, E. (2011). Gene signature in Alzheimer's disease and environmental factors: the virus chronicle. J. Alzheimers Dis. 27, 809-817. doi: 10.3233/JAD-2011-110755

Lin, W. R., Casas, I., Wilcock, G. K., and Itzhaki, R. F. (1997). Neurotropic viruses and Alzheimer's disease: a search for varicella zoster virus DNA by the polymerase chain reaction. J. Neurol. Neurosurg. Psychiatry 62, 586-589. doi: $10.1136 /$ jnnp.62.6.586

Lin, W. R., Wozniak, M. A., Cooper, R. J., Wilcock, G. K., and Itzhaki, R. F. (2002). Herpesviruses in brain and Alzheimer's disease. J. Pathol. 197, 395-402. doi: $10.1002 /$ path.1127

Lin, W. R., Wozniak, M. A., Esiri, M. M., Klenerman, P., and Itzhaki, R. F. (2001). Herpes simplex encephalitis: involvement of apolipoprotein $\mathrm{E}$ genotype. J. Neurol. Neurosurg. Psychiatry 70, 117-119. doi: 10.1136/jnnp.70.1.117

Liu, Y., Li, S., and Wang, Z. (2014). The role of cyclooxygenase in multiplication and reactivation of HSV-1 in vestibular ganglion neurons. ScientificWorldJournal 2014:912640. doi: 10.1155/2014/912640

Lo Presti, A., Weil, A. G., Niazi, T. N., and Bhatia, S. (2015). Herpes simplex reactivation or postinfectious inflammatory response after epilepsy surgery: case report and review of the literature. Surg. Neurol. Int. 6:47. doi: 10.4103/2152-7806.153882

Looker, K. J., Magaret, A. S., May, M. T., Turner, K. M. E., Vickerman, P., Gottlieb, S. L., et al. (2015). Global and regional estimates of prevalent and incident herpes simplex virus type 1 infections in 2012. PLoS One 10:e0140765. doi: 10.1371/journal.pone. 0140765

Lövheim, H., Gilthorpe, J., Johansson, A., Eriksson, S., Hallmans, G., and Elgh, F. (2015). Herpes simplex infection and the risk of Alzheimer's disease: a nested case-control study. Alzheimers Dement. 11, 587-592. doi: 10.1016/j.jalz.2014. 07.157

Miklossy, J., and McGeer, P. L. (2016). Common mechanisms involved in Alzheimer's disease and type 2 diabetes: a key role of chronic bacterial infection and inflammation. Aging 8, 575-588. doi: 10.18632/aging.100921

Miller, R. M., and Federoff, H. J. (2008). Isoform-specific effects of ApoE on HSV immediate early gene expression and establishment of latency. Neurobiol. Aging 29, 71-77. doi: 10.1016/j.neurobiolaging.2006.09.006

Musaeus, C. S., Shafi, M. M., Santarnecchi, E., Herman, S. T., and Press, D. Z. (2017). Levetiracetam alters oscillatory connectivity in Alzheimer's disease. J. Alzheimers Dis. 58, 1065-1076. doi: 10.3233/JAD-160742

Nicoll, J. A. R., Martin, L., Stewart, J., Murray, L. S., Love, S., and Kennedy, P. G. E. (2001). Involvement of apolipoprotein E in herpes simplex encephalitis. Neuroreport 12, 695-698. doi: 10.1097/00001756-200103260-00016

Olsson, J., Lövheim, H., Honkala, E., Karhunen, P. J., Elgh, F., and Kok, E. H. (2016). HSV presence in brains of individuals without dementia: the TASTY brain series. Dis. Model. Mech. 9, 1349-1355. doi: 10.1242/dmm. 026674

Piacentini, R., Li Puma, D. D., Ripoli, C., Marcocci, M. E., De Chiara, G., Garaci, E., et al. (2015). Herpes simplex virus type-1 infection induces synaptic dysfunction in cultured cortical neurons via GSK-3 activation and intraneuronal amyloid-ßprotein accumulation. Sci. Rep. 5:15444. doi: 10.1038/srep15444

Pisa, D., Alonso, R., Fernández-Fernández, A. M., Rábano, A., and Carrasco, L. (2017). Polymicrobial infections in brain tissue from Alzheimer's disease Patients. Sci. Rep. 7:5559. doi: 10.1038/s41598-017-05903-y

Pridgen, W. L., Duffy, C., Gendreau, J. F., and Gendreau, R. M. (2017). A famciclovir + celecoxib combination treatment is safe and efficacious in the treatment of fibromyalgia. J. Pain Res. 10, 451-460. doi: 10.2147/jpr.s127288

Readhead, B., Haure-Mirande, J. V., Funk, C. C., Richards, M. A., Shannon, P., Haroutunian, V., et al. (2018). Multi-scale analysis of independent Alzheimer's 
cohorts finds disruption of molecular, genetic and clinical networks by human herpesvirus. Neuron 99, 64.e7-82.e7. doi: 10.1016/j.neuron.2018. 05.023

Robinson, S. R., and Bishop, G. M. (2002). A $\beta$ as a bioflocculant: implications for the amyloid hypothesis of Alzheimer's disease. Neurobiol. Aging 23, 1051-1072. doi: 10.1016/s0197-4580(01)00342-6

Santana, S., Recuero, M., Bullido, M. J., Valdivieso, F., and Aldudo, J. (2012). Herpes simplex virus type I induces the accumulation of intracellular -amyloid in autophagic compartments and the inhibition of the non-amyloidogenic pathway in human neuroblastoma cells. Neurobiol. Aging 33, 430.e19-430.e33. doi: 10.1016/j.neurobiolaging.2010.12.010

Sawtell, N., Doll, J., Williams, M., and Thompson, R. (2018). Acute and long term outcomes of simulated deep space radiation exposure on latent viral CNS infection and CNS pathology. [\#18166] Available online at: https://three.jsc.nasa.gov/iws/FINAL_2018_HRP_IWS_program.pdf

Sellner, J., and Trinka, E. (2012). Seizures and epilepsy in herpes simplex virus encephalitis: current concepts and future directions of pathogenesis and management. J. Neurol. 259, 2019-2030. doi: 10.1007/s00415-0126494-6

Strandberg, T. E., Pitkala, K., Eerola, J., Tilvis, R., and Tienari, P. J. (2005). Interaction of herpesviridae, APOE gene, and education in cognitive impairment. Neurobiol. Aging 26, 1001-1004. doi: 10.1016/j.neurobiolaging. 2004.09.008

Tsai, M.-C., Cheng, W.-L., Sheu, J.-J., Huang, C.-C., Shia, B.-C., Kao, L.-T., et al. (2017). Increased risk of dementia following herpes zoster ophthalmicus. PLoS One 12:e0188490. doi: 10.1371/journal.pone.0188490

Tyler, K. L. (2015). Editorial commentary: failure of adjunctive valacyclovir to improve outcomes in herpes simplex encephalitis. Clin. Infect. Dis. 61, 692-694. doi: $10.1093 / \mathrm{cid} / \mathrm{civ} 373$

Tzeng, N.-S., Chung, C.-H., Lin, F.-H., Chiang, C.-P., Yeh, C.-B., Huang, S.-Y., et al. (2018a). Anti-herpetic medications and reduced risk of dementia in patients with herpes simplex virus infections-a nationwide, population-based cohort study in taiwan. Neurotherapeutics 15, 417-429. doi: 10.1007/s13311018-0611-x

Tzeng, N.-S., Chung, C.-H., Liu, F.-C., Chiu, Y.-H., Chang, H.-A., Yeh, C.-B., et al. (2018b). Fibromyalgia and risk of dementia-a nationwide, populationbased, cohort study. Am. J. Med. Sci. 355, 153-161. doi: 10.1016/j.amjms.2017. 09.002

Uda, T., Koide, R., Ito, H., Hosono, A., Sunaga, S., and Morino, M. (2013). Relapse of herpes simplex virus encephalitis after surgical treatment for temporal lobe epilepsy: rare complication of epilepsy surgery. J. Neurol. 260, 318-320. doi: 10.1007/s00415-012-6735-8

Wipfler, P., Dunn, N., Beiki, O., Trinka, E., and Fogdell-Hahn, A. (2018). The viral hypothesis of mesial temporal lobe epilepsy-is human herpes virus-6 the missing link? A systematic review and meta-analysis. Seizure 54, 33-40. doi: 10.1016/j.seizure.2017.11.015
Wozniak, M. A., Bell, T., Dénes, Á., Falshaw, R., and Itzhaki, R. F. (2015). AntiHSV1 activity of brown algal polysaccharides and possible relevance to the treatment of Alzheimer's disease. Internat. J. Biol. Macromol. 74, 530-540. doi: 10.1016/j.ijbiomac.2015.01.003

Wozniak, M. A., Frost, A. L., and Itzhaki, R. F. (2009a). Alzheimer's diseasespecific tau phosphorylation is induced by herpes simplex virus type 1 . J. Alzheimers Dis. 16, 341-350. doi: 10.3233/jad-2009-0963

Wozniak, M. A., Mee, A., and Itzhaki, R. (2009b). Herpes simplex virus type 1 DNA is located within Alzheimer's disease amyloid plaques. J. Pathol. 217, 131-138. doi: 10.1002/path.2449

Wozniak, M. A., Frost, A. L., and Itzhaki, R. F. (2013). The helicase-primase inhibitor BAY 57-1293 reduces the Alzheimer's disease-related molecules induced by herpes simplex virus type 1. Antiviral Res. 99, 401-404. doi: 10.1016/j.antiviral.2013.07.003

Wozniak, M. A., Frost, A. L., Preston, C. M., and Itzhaki, R. F. (2011). Antivirals reduce the formation of key Alzheimer's disease molecules in cell cultures acutely infected with herpes simplex virus type 1. PLoS One 6:e25152. doi: 10.1371/journal.pone.0025152

Wozniak, M. A., and Itzhaki, R. F. (2010). Antiviral agents in Alzheimer's disease: hope for the future? Ther. Adv. Neurol. Disord. 3, 141-152. doi: $10.1177 / 1756285610370069$

Wozniak, M. A., and Itzhaki, R. F. (2013). Intravenous immunoglobulin reduces $\beta$ amyloid and abnormal tau formation caused by herpes simplex virus type 1 . J. Neuroimmunol. 257, 7-12. doi: 10.1016/j.jneuroim.2013.01.005

Wozniak, M. A., Itzhaki, R. F., Shipley, S. J., and Dobson, C. B. (2007). Herpes simplex virus infection causes cellular $\beta$-amyloid accumulation and secretase upregulation. Neurosci. Lett. 429, 95-100. doi: 10.1016/j.neulet.2007. 09.077

Wozniak, M. A., Shipley, S. J., Combrinck, M., Wilcock, G. K., and Itzhaki, R. F. (2005). Productive herpes simplex virus in brain of elderly normal subjects and Alzheimer's disease patients. J. Med. Virol. 75, 300-306. doi: 10.1002/jmv.20271

Zambrano, A., Solis, L., Salvadores, N., Cortés, M., Lerchundi, R., and Otth, C. (2008). Neuronal cytoskeletal dynamic modification and neurodegeneration induced by infection with herpes simplex virus type 1. J. Alzheimers Dis. 14, 259-269. doi: 10.3233/jad-2008-14301

Conflict of Interest Statement: The author declares that the research was conducted in the absence of any commercial or financial relationships that could be construed as a potential conflict of interest.

Copyright (C) 2018 Itzhaki. This is an open-access article distributed under the terms of the Creative Commons Attribution License (CC BY). The use, distribution or reproduction in other forums is permitted, provided the original author(s) and the copyright owner(s) are credited and that the original publication in this journal is cited, in accordance with accepted academic practice. No use, distribution or reproduction is permitted which does not comply with these terms. 